Assessing patients for mental health review tribunals, I have noted that many teams often simply discharge patients when they do not cooperate with follow-up. The 'positive attitude of hope and recovery', adopted by some community teams and encouraged in New Ways of Working, ${ }^{2}$ fails to acknowledge the typically chronic or relapsing course of schizophrenia. New Ways of Working also appears to discourage consultant psychiatrists from engaging in long-term follow-up by talking of a 'shrinking and more focused role for senior professionals, shedding repetitive activities or doing them more smartly'. These approaches and the fragmentation of services into myriad teams risk losing opportunities to form and maintain therapeutic relationships with patients and their families, and to gain understanding of the longterm course of patients' illnesses. It can subsequently become a bewildering task for families of discharged patients, or for concerned others, to receive help. When they do make contact, this will often be with professionals unknown to the patient and to whom the patient is unknown.

Given the increased investment and increased numbers of psychiatrists documented in New Ways of Working, it is difficult to see why psychiatrists and other professionals should have less time to allocate to the important task of maintaining links with this high-priority group. The 2007 progress report on New Ways of Working states: 'The aim is to achieve a cultural shift in services that enables those with the most experience and skills to work face to face with those with the most complex needs.' ${ }^{3}$ Schizophrenia is a severe and usually chronic or recurrent illness associated with a high suicide risk and relatively high homicide risk. It is commonly associated with substance misuse. Long-term prophylactic medication and psychological and psychosocial interventions can reduce relapse rates. Long-term medical treatment carries risks of adverse effects. Consultant psychiatrists are commonly among the longest-serving members of their teams. The complex elements of schizophrenia and the advantages of long-term follow-up provide an important and valid role for psychiatrists.

The Inquiry should gather data on how many of those with schizophrenia, committing homicide, have been under psychiatric care, how and why they ceased to be so, and in how many cases others had been trying to involve psychiatric services prior to the homicide. There may be a lesson that long-term follow-up of patients with schizophrenia is justified, even if the patient appears well.

1 National Confidential Inquiry into Suicide and Homicide by People with Mental IIIness. Annual Report: England and Wales. The University of Manchester, 2009 (http://www.medicine.manchester.ac.uk/psychiatry/research/suicide/ prevention/nci/inquiryannualreports/AnnualReportJuly2009.pdf).

2 Royal College of Psychiatrists, National Institute for Mental Health in England. New Ways of Working for Psychiatrists: Enhancing Effective, Person-Centred Services Through New Ways of Working in Multidisciplinary and Multi-agency Contexts. Final report 'but not the end of the story'. Department of Health, 2005.

3 Department of Health. Mental Health: New Ways of Working for Everyone. Developing and Sustaining a Capable and Flexible Workforce. Progress Report. Department of Health, 2007 (http://www.dh.gov.uk/ prod_consum_dh/groups/dh_digitalassets/@dh/@en/documents/digitalasset/ dh_074495.pdf).

George J. Lodge, Bradford-on-Avon Health Centre, Station Approach, Bradford-on-Avon, Wiltshire BA15 2SE, UK. Email: george.lodge@doctors.org.uk

doi: 10.1192/bjp.195.6.553b

\section{Childhood neuropsychological deficits and adult OCD}

We read Grisham et als paper ${ }^{1}$ with some concerns. Without doubt, the study - using longitudinal data instead of cross-sectional designs as in previous studies - adds positively to the subject area, which has not been well researched and the results of which are far from conclusive. However, we have a number of concerns about the reported results.

This study represents only one type of population and also, owing to the small number of obsessive-compulsive disorder (OCD) cases (only 13/700) found in this study, the authors' statement of 'individuals with OCD have premorbid impairment in visuospatial abilities and some forms of executive functioning, consistent with biological models of OCD' will be considered an overstatement and cannot be generalised to other population subsets.

We know that a previous study of OCD with the same birth cohort at age 18 found that the OCD group did not differ significantly on any of the neuropsychological tests at age $13,{ }^{2}$ and it will be interesting to know whether there were any associations at ages 15, 21 and 26, ages at which Grisham et al's cohort was also assessed. Although participants in Grisham et al's study were assessed at 3, 5, 7, 9 and 11 years of age, according to their performance on neuropsychological tests there is some evidence to suggest that there is no cognitive impairment in children with OCD, and that OCD symptoms may not interfere with cognitive abilities early on in the illness. ${ }^{3}$ However, disturbance of cognitive functions may become significant over time, as we know that psychotropic medications are the main pharmacological treatment that may also influence neuropsychological function. ${ }^{4}$ Neuroimaging studies suggest that the basal ganglia and ventral prefrontal cortex are most frequently implicated in OCD in adults. If brain dysfunction underlies OCD, decrements on neuropsychological tests should be found. ${ }^{3}$ With this in mind, it is difficult to understand how people had neuropsychological deficits prior to developing OCD, when evidence suggests that children with OCD do not exhibit significant cognitive deficits early in the illness.

Evidence is in favour of executive dysfunction and auditory attention problems in late-onset OCD (age 13-17) rather than the early-onset (prior to 12 years) disorder. Performing poorly on the neuropsychological tests is not very conclusive as they may help to identify a dysfunction in a particular anatomical area, but provide little evidence on the actual cause leading to the pathology. Late-onset OCD is also associated with poorer visual memory relative to healthy comparison groups. Roth et al's findings ${ }^{5}$ suggest that early- and late-onset OCD may be the result of at least partially differing neurobiological mechanisms.

There is not much evidence at present to show the effects of therapeutic interventions on neuropsychological deficits in OCD, ${ }^{6}$ and if any, are they curative in order to avoid the illness in future? The majority of people who had OCD also had comorbid illnesses - was it these illnesses that were the cause of neuropsychological deficits that later led to developing OCD (chemical abnormalities such as serotonin)? Perhaps studies on this aspect may be an area of interest for the authors.

The number of participants in the study is so small that no definitive statements should be made at this stage. We also wonder whether there are children and adolescents with neuropsychological deficits but not diagnosable psychiatric disorders and how we might compare them with individuals with conditions such as OCD.

1 Grisham JR, Anderson TM, Poulton R, Moffitt TE, Andrews G. Childhood neuropsychological deficits associated with adult obsessive-compulsive disorder. Br J Psychiatry 2009; 195: 138-41.

2 Douglass HM, Moffitt TE, Dar R, McGee R, Silva P. Obsessive-compulsive disorder in a birth cohort of 18-year-olds. Prevalence and predictors. J Am Acad Child Adolesc Psychiatry 1995; 34: 1424-31. 
3 Beers SR, Rosenberg DR, Dick EL, Williams T, O'Hearn KM, Birmaher B, et al. Neuropsychological study of frontal lobe function in psychotropic-naive children with obsessive-compulsive disorder. Am J Psychiatry 1999; 156: 777-9.

4 Hollander E, Schiffman E, Cohen B, Rivera-Stein MA, Rosen W, Gorman JM, et al. Signs of central nervous system dysfunction in obsessive-compulsive disorder. Arch Gen Psychiatry 1990; 47: 27-32.

5 Roth RM, Milovan D, Baribeau J, O'Connor K. Neuropsychological functioning in early- and late-onset obsessive-compulsive disorder. J Neuropsychiatry Clin Neurosci 2005; 17: 208-13.

6 Bolton D, Raven P, Madronal-Luque R, Marks IM. Neurological and neuropsychological signs in obsessive compulsive disorder: interaction with behavioural treatment. Behav Res Ther 2000; 38: 695-708.

Imran Mushtaq, Northampton Child and Adolescent Mental Health Service, 8 Notre Dame Mews, Northampton NN1 2BG, UK. Email: imranmushtaq@doctors.org.uk; Muhammad Nabeel Helal, Cabot Child and Adolescent Mental Health Service, Bristol, UK

doi: 10.1192/bjp.195.6.554

Authors' reply: Although Drs Mushtaq \& Helal noted the need for longitudinal studies in this area, they expressed several concerns, one regarding the small number of individuals with OCD in our study. We agree and noted this limitation in our original paper. We were constrained, however, by the prevalence of OCD in the population; the proportion of cohort members diagnosed with OCD at age 32 in our study $(1.9 \%)$ was consistent with other epidemiological studies. Our conclusions nonetheless remain tentative until they may be replicated in another longitudinal study.

Drs Mushtaq \& Helal also referred to a previously published study by our group, which examined risk factors for an OCD diagnosis at age 18 . We have suggested that this discrepancy may be related to changes in the OCD criteria from DSM-III to DSM-IV, which reduced the reported prevalence of the disorder in the general population. ${ }^{1}$ Study members diagnosed with OCD at age 32 may have represented a more severe and persistent subgroup relative to the larger proportion (4\%) of cohort members diagnosed with OCD at age 18 .

They refer to a cross-sectional study, conducted by Beers et al, that failed to find cognitive deficits in a group of 21 children diagnosed with OCD. ${ }^{2}$ Although this study made a valuable contribution, the authors themselves noted the need to supplement their findings with results from 'carefully designed longitudinal studies.' ${ }^{3}$ We suspect that the discrepancy between the results of this earlier study and our recent findings may be partially attributable to sampling differences, including referral bias. Participants in the earlier study were paediatric patients with OCD at a prestigious psychiatric institute, whereas the Dunedin cohort comprises a non-treatment-seeking population cohort from a range of socioeconomic backgrounds. Further, in the previous study, children with OCD who had a lifetime history of any other psychiatric diagnosis were excluded. ${ }^{2}$ Obsessivecompulsive disorder, like most emotional disorders, is highly comorbid with other psychiatric conditions. ${ }^{4}$ Although creating a 'pure' OCD group eliminates the influence of comorbid disorders, this advantage must be weighed against the likelihood of creating a non-representative, potentially less severe subgroup. Our study aimed to test for neuropsychological risk factors for adult OCD, as it presents in the general population, including comorbidity, and regardless of referral and treatment seeking. Thus, our study's aims, design and inferences differed decidedly from those of Beers et al.

Finally, Drs Mushtaq \& Helal made the valid point that poor performance on neuropsychological tests may help to localise dysfunction in particular neuroanatomical substrates, but it does not provide conclusive evidence for the cause of the pathology. Although our results are consistent with research that has demonstrated that children with OCD already show abnormalities in frontal and striatal volumes relative to comparison participants, ${ }^{5}$ we do not suggest that we have provided definitive evidence of causality. Obsessive-compulsive disorder is likely to be multiply determined and not all participants with particular neuropsychological deficits will go on to develop this disorder.

1 Crino R, Slade T, Andrews G. The changing prevalence and severity of obsessive-compulsive disorder criteria from DSM-III to DSM-IV. Am J Psychiatry 2005; 162: 876-82.

2 Beers SR, Rosenberg DR, Dick EL, Williams T, O'Hearn KM, Birmaher B, et al. Neuropsychological study of frontal lobe function in psychotropic-naive children with obsessive-compulsive disorder. Am J Psychiatry 1999; 156 777-9.

3 Beers SR, Rosenberg DR, Ryan CM. Cognitive deficits in obsessive-compulsive disorder: Dr Beers and colleagues reply. Am J Psychiatry 2000; 157: 1183.

4 Brown TA, Campbell LA, Lehman CL, Grisham JR, Mancill RB. Current and lifetime comorbidity of the DSM-IV anxiety and mood disorders in a large clinical sample. J Abnorm Psychology 2001; 110: 585-99.

5 Rosenberg DR, Keshavan MS. Toward a neurodevelopmental model of obsessive-compulsive disorder. Biol Psychiatry 1998; 43: 623-40.

Jessica R. Grisham, School of Psychology, University of New South Wales, Sydney, Australia 2052. Email: jessicag@unsw.edu.au; Terrie E. Moffitt, Institute of

Psychiatry, King's College London, UK and Duke University, Durham, North Carolina, USA; Richie Poulton, Dunedin School of Medicine, University of Otago, New Zealand.

doi: 10.1192/bjp.195.6.555

\section{James Joyce and Asperger syndrome}

As an Irishman, I was pleased to learn both of Peter Tyrer's Celtic heritage and of his inclusion of Ulysses in his list of 'ten books.' I agree with Tyrer that the sheer poetic beauty and creative manipulation of language make this book a great work. The author correctly points out Joyce's amazing ability to describe emotions with both beauty and precision. I would like to add to this issue further; I believe it is Joyce's description of complex feeling states that is one of the supreme facets of Ulysses. In drawing a distinction between emotions and feelings I do so in the same sense that Antonio Damasio does, ${ }^{2}$ i.e. that feelings represent a composite of often numerous emotions further elaborated by various thought processes and felt in the viscera or body.

Joyce captures subtle feeling states so well that I was surprised to find, upon a recent trip to the 'auld sod', a book in a Dublin airport store suggesting that Joyce had Asperger syndrome. ${ }^{3}$ I thought it a somewhat odd hypothesis that a man who could describe emotions/feelings so well would have a disorder whose key pathology is an impaired theory of mind. As Tyrer alludes, Joyce's use of the 'stream of consciousness' technique in his writing is much more akin to thought disorder - this was particularly true of his last book, Finnegan's Wake. Although Joyce experienced certain difficulties in this life, there is little evidence to suggest he was ever psychotic; and his creative deconstruction of language was no doubt a reflection of his genius for writing. However, Joyce had a daughter who developed schizophrenia so if there was a suggestion of mental illness influencing his work, a psychotic trait seems a more plausible thesis to me than Asperger syndrome.

The second aspect of Tyrer's article that I enjoyed was his anecdote of the late, great Aubrey Lewis berating a psychiatry trainee at the Maudsley Hospital for failing to have 